\title{
An Experimental Study of Retailer-Brand Collaboration: Duration and Perceived Fit Towards Consumer Behavior
}

\author{
Anindhitya Andriani ${ }^{1,}$ Tengku Ezni Balqiah *2 \\ ${ }^{1}$ Faculty of Economics and Business, Universitas Indonesia \\ ${ }_{*}^{2}$ Faculty of Economics and Business, Universitas Indonesia \\ Corresponding author.Email: tengk u.ezni@ui.ac.id
}

\begin{abstract}
Indonesian retailers such as department stores tend to use sales promotions by discounting items, which has caused the consumer to be less likely to pay at fu 11 price and learn to postpone their purchase. Therefore, this study investigates the effects of limited-edition strategy in a retailer-brand collaboration on consumer behaviors, i.e., the urgency to buy. Analysis of variance was conducted to test a $2 \times 2$ between-subjects design $(n=277)$. The result shows that the urgency to buy is favorable among participants when the collaboration product is offered as limited-edition and has a high perceived retailer-brand fit. This study contributes to marketing literature in the space of the effectiveness of brand alliances and limited -edition strategy. Further, this study provides insights for managers to design competitive marketing strategies by exciting consumers to purchase right away without marking the product on sale.
\end{abstract}

Keywords: Retailer-brand collaboration, Limited-edition strategy, Perceived Retailer and Brand Fit”, Urgent purchase behavior.

\section{INTRODUCTION}

Department stores in Indonesia have experienced a decline in sales performance over the past few years. The impact of this issue has been proven by the shutdown of several department store outlets that have stopped operating [1]. This is mainly due to the increasing competition in the retail industry, especially after several competitors such as $\mathrm{H} \& \mathrm{M}$, Zara, and UNIQLO entered Indonesia's retail sector [1]. In addition, the decline is also predicted to occur due to the behavior of department store consumers who tend to delay purchases and wait for the desired product to be sold at a discount [2]. Such buying behavior put retailers in an unfavorable position, because not only do consumers choose to delay purchases, but they also prefer to pay half $\mathrm{p}$ rice, which causes the slowing sales growth [2][3].

In recent research, Euro monitor provided insights into how department stores in Indonesia can survive the retail industry competition, that is, to gain a new competitive advantage [1]. A previous study showed that one of the strategies that can give department stores a new competitive advantage is collaborating with well known brands, especially among target consumers [3]. Through collaboration, retailers can increase their competitive advantage, while brands can attract attention and publicity [4][5]. However, department stores need to consider the level of fit between the brands involved in a collaboration. The fit is considered important because it might cause a financial impact on the parties involved and their brand image [6]. It also determines the appropriate promotional strategies in marketing collaborative products [5][6]. Considerations related to fit are also essential in retailers' efforts to create collaborative concepts that are considered unique and exclusive to encourage consumers to respond positively [6].

Previous study also proves that implementing a scarcity strategy in a collaboration can result in intense purchasing behavior among consumers, such as impulsive buying [3]. This buying behavior causes make an unplanned purchase, triggered by emotions. It was specifically mentioned that the brand collaboration strategy's success and the limited-edition strategy are characterized by positive buying behavior [7]. While previous research was conducted in the United States, this study wanted to test whether a retailer-b rand collaboration strategy that was offered on a limited basis could produce the same purchasing behavior among Indonesian consumers. Hence, this study examines the effectiveness of implementing limited collaboration duration and controlling the fit of the collaborating retailer-brand on consumer behavior. 


\section{LITERATURE REVIEW}

\subsection{Perceived Scarcity in Limited -Edition Strategy}

Studies have shown a relationship between the effects of scarcity and consumer perceptions of signaled products [8]. One theory that supports this relationship is the commodity theory, where a product will be considered more valuable when the product is scarce

[9]. Th is theory implies that the rarer the product, the more valuable and desired by consumers [7].

Meanwhile, based on the theory of cognitive resources, an individual has certain cognitive capacities that can be used to perform various tasks. The more cognitive resources are used, the harder it will be for someone to pay attention to their surrounding [10]. In the context of scarcity appeals and messages, time pressure and limited-edition signals can influence consumer shopping behavior by affecting consumers' ability to process information [11][12]. Their cognition focuses on scarcity and time pressures messages. In other words, as long as there are signals that indicate a product as a limited edition, the consumer will perceive the additional value of the goods being offered, and they will consider other potential buyers as a competitive threat. This could consequently encourage them to show aggressive buying behavior [13], such as impulsive behavior in buying.

The concept of urgency to buy is defined as the urgent desire to purchase products immediately that arise due to marketer or companies limiting consumers' freedom to take their time of considering alternative decisions [14][15]. External factors and internal factors can drive the urgency of consumers to buy. As the internal factors cannot be controlled [3][16], marketers tend to focus on external factors that can drive consumers to buy through marketing and advertising strategies. This way, marketers can take advantage of the effective components in the product experience that can be offered to encourage unplanned purchases, even to the point where consumers are motivated to buy

Participants' aggressively [17]. Based on this explanation, we proposed the following hypothesis:

H1:

urgency to purchase is stronger

when the product is offered as limited-edition than ongoing collections.

\subsection{Fit between Retailer and Brand}

To generate a positive evaluation and purchase intention, consumers need to understand the compatibility of the partnered brands [18][19][20]. Several studies that discuss retailer-brand collaboration have found that retailer-b rand compatibility can affect the attitudes, evaluations, and consumer behavior toward the collaboration [3][5]. Therefore, it imp lies that the main key to a successful collaboration is how the company chooses its brand partner and how consumers perceive the partnered brand [19][20][21]. This expectation will influence consumer evaluation, which in turn will affect consumer purchasing intentions. Therefore, we proposed the following hypothesis:

H2: Participants' urgency to purchase is stronger when the fit between retailer and brand perceived as high than when the fit perceived as low.

\subsection{Combined Effect of Limited-Edition Strategy and Perceived Fit between Retailer and Brand}

One of the goals of collaboration as a marketing strategy is to differentiate a brand from competitors through novelty elements, to enhance the image of each partnered brand [22]. However, marketers need to pay attention to the retailer and brand's compatibility. Positive perceptions of retailer and brand compatibility can result in positive consumer attitudes and assessments to produce positive purchase intention [5]. On the other hand, previous research has shown that in brand alliances, brand reputation or prestige have a different effect from the duration of collaboration [23]. Both aspects determine the success of the brand collaboration, but compared to reputation, which takes a long time to be obtained, the duration is a variable that is easier to control by managers [23][3]. Thus, by offering exclusivity in the form of time and supply restrictions that are only available at certain retailers, consumers can signal that they have good taste and deserve to be admired by the people around them [24]. In reference to the explanation above, we proposed the following hypothesis:

H3. For the high perceived fit retailer-brand collaboration, participants' urgency to purchase is stronger when the collaboration product as limited edition rather than ongoing collections.

\section{RESEARCH METHODOLOGY}

Figure 1 depicts the theoretical frameworks used in this study. It was adapted from [3]. In reference to the previous literature finding that retailers must decide the duration of the collaboration and consider the fit between the collaborating retailer and brand to produce urgent consumers' behavioral intention, such as urgency to buy, we investigate each factor's direct effect, the interaction of two factors, and the interaction of two factors on the urgency to buy. 


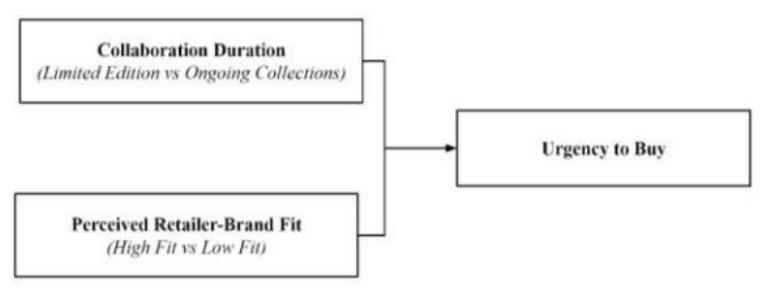

Figure 1 Research Framework [3]

\subsection{Experimental Study}

We conducted a between-subject experimental study with a 2 (collaboration duration: limited-edition versus ongoing collection; manipulated factor) x 2 (perceived retailer-brand fit: high versus low; manipulated factor) design using an online questionnaire with four sets of stimuli. In the beginning, we randomized the stimuli by asking the participants to choose a number (1) to (4) that lead them to their assigned manipulation.

\subsection{Measures}

The manipulation check for each stimulus was adapted from [25][8][3]. After the participants are exposed to the stimuli, we instructed them to rate their urgency to purchase using a three-item adapted form

[16]. A 11 the questionnaire measurements use a fivepoint Likert scale. We performed a validity and reliability test, and the result shows that all the items are valid (factor loading: 0.728 - 0.970) and reliable (Cronbach's alpha: $0.707-0.920$ ).

\subsection{Pilot Test}

This study used a combination of high-end product brands and high/low-end department stores brands to manipulate perceived retailer-brand fit. When conducting a study of company strategy, researchers commonly use real company names [26][27][28][3]. Therefore, we performed pilot tests to (1) compile and

(2) select the product category, high end/low-end product brand, and department stores. Once the components were selected, we edited the advertisement video to include a manipulated text message adapted

from [3]. Each stimulus used the same video advertisement, except for the text manipulation and the product brand and retailer name. Based on the majority results $(\mathrm{n}=57)$, we selected bag as the product category $(43,9 \%)$, Louis Vuitton as the high-end product brand

$(24,7 \%)$, Seibu Department Store as the high -end retailer (29\%), and Matahari Department Store as the low-end retailer $(26,5 \%)$. Based on the pilot test result, we developed four sets of stimuli that contain manipulations of collaboration duration and high/low fit collaboration. Manipulation checks were performed to ensure that the participants understand the manipulation exhibited in each stimulus.

\section{RESULT AND DISCUSSION}

\subsection{Main Test}

To test the proposed hypotheses, we collected data using an online questionnaire. The participants consist of 277 are actively working females. We used female participant data only because fashion products are often targeted toward female consumers [29]. As this research focused on the collaboration of high-end product brands and retailers, we decided that only respondents could afford branded products [30]. Therefore, we only use the data of actively working participants and had not experienced a decline in income due to COVID-19 being eligible to participate.

The manipulation checks result suggested that the participants agree that the high fit stimulus was perceived as a higher level of retailer-b rand fit $(M=2.937)$ compared to the lo $\mathrm{w}$ fit one $(\mathrm{M}=2.131)$. Meanwhile, the manipulation checks result indicated that the participants exposed to the limited-edition stimulus $(M=2.786)$ perceived the product offered to be scarcer than those exposed to ongoing collection one $(\mathrm{M}=2.281)$.

\subsubsection{The effect of duration and perceived retailer-brand fit}

\subsubsection{Collaboration duration: Limited edition vs ongoing collection}

In testing hypothesis $1(\mathrm{n}=277)$, a one-way analysis of variance revealed that there was a statistically significant effect of duration on the urgency to buy [F $(1,270)=18.524, p=0.000]$. Bonferroni post-hoc result indicated that the mean score of the urgency to purchase for the collaboration offered in the limited edition $(\mathrm{M}=2.384, \mathrm{SD}=0.892)$ was significantly different from the ongoing collection one $(\mathrm{M}=1.892, \mathrm{SD}=0.671)$. The result suggests that the participants exhibited a higher urge to purchase immediately when the collaboration is offered in limited edition. Therefore, we conclude that H1 can be accepted.

\subsubsection{Perceived retailer-brand fit: High fit $v$ s low fit}

In testing hypothesis $2(\mathrm{n}=277)$, ANOVA result revealed that there was a statistically significant effect of perceived fit on the urgency to buy $[F(1,271)=$

4.532, $\mathrm{p}=0.034]$. Bonferroni post-hoc result indicated that the mean score of the urgency to purchase for the collaboration perceived as highly fit $(\mathrm{M}=2.510, \mathrm{SD}=$ 
0.876) was significantly different than the collaboration perceived as lo $\mathrm{w}$ fit $(\mathrm{M}=1.760, \mathrm{SD}=0.561)$. The result suggests that the participants exhibited a higher urge to purchase immediately when the retailer and product brand in the collaboration are highly compatible. Therefore, we conclude that $\mathrm{H} 2$ can be accepted.

Table 1. ANOVA Results

\begin{tabular}{|l|r|r|r|r|r|r|}
\hline \multicolumn{1}{|c|}{ Source } & $\begin{array}{r}\text { Type III Sum } \\
\text { of Squares }\end{array}$ & df & Mean Square & F & $\begin{array}{r}\text { Sig. } \\
\text { Squartial Eta }\end{array}$ \\
\hline Intercept & 1220.635 & 1 & 1220.635 & 3045.422 & 0.000 & 0.91773 \\
\hline Collaboration Duration & 14.536 & 1 & 14.536 & 18.524 & 0.000 & 0.11726 \\
\hline Perceived Retailer-Brand Fit & 28.695 & 1 & 28.695 & 4.532 & 0.034 & 0.20770 \\
\hline Collaboration Duration * & 0.29 & 1 & 0.29 & 0.073 & 0.788 & 0.00027 \\
Perceived Retailer-Brand Fit & 109.421 & 273 & 109.421 & & & \\
\hline Error & 1375.250 & 277 & 1375.250 & & & \\
\hline Total & & & &
\end{tabular}

4.2.2. The effect of two-way interaction: Collaboration duration $x$ perceived retailerbrand fit

In testing the effect of two-way interaction $(n=277)$, we performed a two-way analysis of variance (ANOVA) to test the interaction effect of duration and perceived retailer-brand fit. The result (Tab le 1) revealed that the combined effect of duration and

perceived fit does not reach the conventional significance level $[F(1,273)=0.073, p=0.788$, np2 $=$ 0.002] on urgency to buy. Nonetheless, the participants exhibited a stronger urge to buy the collaboration product when the highly perceived fit collaboration was offered in limited edition $(\mathrm{M}=2.665$, $\mathrm{SD}=0.805)$ than an ongoing collection ( $\mathrm{M}=2.185, \mathrm{SD}=0.579)$. As there is no significant interaction effect, the main effects exhibited a significant effect $(p=0.000)$. To interpret the results, partial eta squared value represents the

relative impact of perceived retailer -brand fit $(\mathbf{\eta p} 2=$ $0.207)$ compared to collaboration duration $(\boldsymbol{\eta p} 2=\mathbf{0 . 1 1 7})$, which means that perceived retailer-brand fit has an effect that is twice as strong as collaboration duration. Based on the result, we conclude that $\mathrm{H} 3$ cannot be accepted.

\section{CONCLUSIONS AND IMPLICATIONS}

The results show that the limited-edition strategy has a superior effect across all behaviors tested in this study: the urgency to buy. This study's findings support retailers to limit collaboration (time or quantity) to reduce consumer intentions to delay purchases [3]. Th is form of limited-edition strategy has proven effective in consumers' intentions to purchase the product [31] in fear that they will not be able to purchase the product in the near future.

In implementing collaboration, retailers need to consider the level of fit, as it was proven to affect consumer perceptions and evaluation. This study's findings prove that high-end retailers should collaborate with brands of the same or higher class. Meanwhile, these findings suggest that collaborating with higher-end brands does not impact high-end retailers for lower-end retailers. In other words, the findings of this study support lower-end retailers to collaborate with product brands that have the similar level of quality, prestige, price, and image. It indicated that when the fit between the collaborating brands is perceived as high, the consumer will show a stronger positive behavior [3]. However, based on the finding of the combined effect, it can be stated that for behavior as intense as urgency to buy, retailers need to consider the brand partner who can enhance the retailer's brand image instead of overshadowing it.

\section{AUTHORS' CONTRIBUTIONS}

A.A. carried out the experiment. T.E.B. supervised the process and the findings of this wo rk. Both authors provided feedback and shape the research and analysis.

\section{REFERENCES}

[1] Euro monitor International (2020). Department Stores in Indonesia: Country Report 2020.

https://www.euro monitor.co m/departmentstores-in-indonesia/report

[2] Levy, M., \& Weitz, B. A. (2004). Retailing management. McGraw-Hill/Irwin. 
[3] Childs, M., \& Jin, B. E. (2020). Retailer-brand collaborations: testing key strategies to increase consumers' urgency to buy. International Journal of Retail \& Distribution Management. DOI: 10.1108/IJRDM -06-2019-0199

[4] Kunde, A. (2012). Two reasons why H\&M's designer collaborations are here to stay. Passport by Euromonitor.

[5] Wang, S. C., Soesilo, P. K., \& Zhang, D. (2015). Impact of luxury brand retailer co-branding strategy on potential customers: A cross -cultural study. Journal of International Consumer

Marketing, 27(3), 237-252. DOI:

https://doi.org/10.1080/ 08961530.2014.970320

[6] White, M. (2013), " Epic retail fail: where did the Target p Neiman Marcus collection go wrong?", available at: http://business.time.co m/2013/01/02/ epic-retail-fail-where-did-the-target-neiman marcus -collection-go-wrong/ (accessed at 30 December 2020).

[7] Lynn, M. (1992). The psychology of unavailability: Exp laining scarcity and cost effects on value. Basic and Applied Social Psychology, 13(1), 3-7. DOI: https://doi.org/10.1207/s15324834basp1301_2

[8] Wu, W. Y., Lu, H. Y., Wu, Y. Y., \& Fu, C. S. (2012). The effects of product scarcity and consumers' need for uniqueness on purchase intention. International Journal of Consumer Studies, 36(3), 263-274. DOI: https://doi.org/10.1111/j.1470-6431.2011.01000.x

[9] Brock, T. C. (1968). Implications of commodity theory for value change. In Psychological foundations of attitudes (pp. 243-275). Academic Press. DOI: https://doi.org/10.1016/B978-1-48323071-9.50016-7

[10] Goldstein, E. B. (2011). Introduction to cognitive psychology. In Cognitive psychology: Connecting mind, research, and everyday experience (3rd ed., p. 87). Australia: Wadsworth Cengage Learning.

[11] Park, C. W., Iyer, E. S., \& Smith, D. C. (1989). The effects of situational factors on in-store grocery shopping behavior: The role of store environment and time availab le for shopping. Journal of consumer research, 15(4), 422-433. DOI: https://doi.org/10.1086/209182

[12] Svenson, O., \& Maule, A. J. (Eds.). (1993). Time pressure and stress in human judgment and decision making. Springer Science \& Business Media.

[13] Kristofferson, K., McFerran, B., Morales, A. C., \& Dahl, D. W. (2017). The dark side of scarcity promotions: how exposure to limited -quantity promotions can induce aggression. Journal of Consumer Research, 43(5), 683-706. DOI: https://doi.org/10.1093/jcr/ucw056

[14] Breh m, S. S., \& Breh m, J. W. (2013). Psychological reactance: A theory of freedom and control. Academic Press.

[15] Clee, M. A., \& Wicklund, R. A. (1980). Consumer behavior and psychological reactance. Journal of consumer research, 6(4), 389-405. DOI: https://doi.org/10.1086/208782

[16] Gupta, S. (2013). The psychological effects of perceived scarcity on consumers' buying behavior.

[17] Bagozzi, R. P., Gopinath, M., \& Nyer, P. U. (1999). The role of emotions in marketing. Journal of the academy of marketing science, 27(2), 184206.

[18] Park, C.W., Jun, S.Y. and Shocker, A.D. (1996), "Composite branding alliances: an investigation of extension and feedback effect", Journal of Marketing Research, Vo 1. 33 No. 4, pp. 453-466. DOI: https://doi.org/10.2307/3152216

[19] Simon in, B.L. and Ruth, J.A. (1998), "Is a company known by the company it keeps?

Assessing the spillover effects of brand alliances on consumer brand attitudes", Journal of Marketing Research, Vol. 35, February, pp. 30-42. DOI: https://doi.org/10.2307/3151928

[20] Ho, R. (2013). Handbook of univariate and multivariate data analysis with IBM SPSS. CRC press.

[21] Rao, A. and Ruekert, R.W. (1994), "Brand alliances as signals of product quality", Sloan Management Review, 36: 87-97.

[22] Kim, K., Park, J., \& Kim, J. (2014). Consumerbrand relationship quality: When and how it helps brand extensions. Journal of Business Research, 67(4), 591-597. DOI: https://doi.org/10.1016/j. jbusres.2013.03.001

[23] Purohit, D., \& Srivastava, J. (2001). Effect of manufacturer reputation, retailer reputation, and product warranty on consumer judgments of product quality: A cue diagnosticity framework. Journal of Consumer Psychology, 10(3), 123-134. DOI: https://doi.org/10.1207/s15327663jcp1003_ 1

[24] Gierl, H., \& Huettl, V. (2010). Are scarce products always more attractive? The interaction of different types of scarcity signals with products' suitability for conspicuous consumption. International Journal 
of Research in Marketing, 27(3), 225-235. DOI:

https://doi.org/10.1016/j.ijresmar.2010.02.002

[25] Eisend, M. (2008). Explaining the impact of scarcity appeals in advertising: The mediating role of perceptions of susceptibility. Journal of

Advertising, 37(3), 33-40. DOI: https://doi.org/10.2753/JOA0091-3367370303

[26] Aaker, D. A., \& Keller, K. L. (1990). Consumer evaluations of brand extensions. Journal of marketing, $\quad 54(1), \quad 27-41 . \quad$ DOI: https://doi.org/10.2307/1252171

[27] D'Astous, A., \& Boujbel, L. (2007). Positioning countries on personality dimensions: Scale development and imp lications for country marketing. Journal of Business Research, 60(3), 231-239. DOI: 10.1016/j.jbusres.2006.11.005

[28] Decker, C., \& Baade, A. (2016). Consumer perceptions of co-branding alliances: Organizational dissimilarity signals and brand fit. Journal of brand management, 23(6), 648-665. DOI: $10.1057 / \mathrm{s} 41262-016-0013-5$ [53] Liao \& Wang 2009

[29] Liao, J., \& Wang, L. (2009). Face as a mediator of the relationship between material value and brand consciousness. Psychology \& Marketing, 26(11), 987-1001. DOI: https://doi.org/10.1002/mar.20309

[30] Pino, G., Amatulli, C., Peluso, A. M., Nataraajan, R., \& Guido, G. (2019). Brand prominence and social status in luxury consumption: A comparison of emerging and mature markets. Journal of Retailing and Consumer Services, 46, 163-172. DOI: https://doi.org/10.1016/j.jretconser.2017 .11 .006

[31] Ferreira, C. (2017), "While supplies last: how to use scarcity and urgency to increase sales", available at: https://www.shopify.co $\mathrm{m} / \mathrm{blog} / 48515717$-while - supplies-last-how-to-usescarcity-and-urgency-to-increase-sales (accessed at 30 December 2020) 